\title{
Sensorial profile, content, and antioxidant activity in coffee beverages prepared by direct contact methods
}

\author{
Angela María Ormaza-Zapata ${ }^{1}$ D , Félix Octavio Díaz-Arango ${ }^{1 D}$, Benjamín Alberto Rojano²
}

${ }^{1}$ Universidad de Caldas, Manizales, Caldas, Colombia.

${ }^{2}$ Universidad Nacional de Colombia, Medellín, Antioquia, Colombia.

Contact authors: angela.ormaza@ucaldas.edu.co,felix.diaz@ucaldas.edu.co,brojano@unal.edu.co

Received in May 1, 2020 and approved in November 9, 2020

\section{ABSTRACT}

Direct content coffee preparation methods may be used as alternative ways to obtain coffee beverages with varied cup profiles. In this investigation the antioxidant metabolites, antioxidant activity, and cup profiles were determined for coffee drinks prepared using five different direct contact methods. The method that registered greatest antioxidant retention was Ibrik, followed by French press, and Toddy. Antioxidant capacity was proportional to antioxidant component retention in the preparations made. It is recommended that coffee be prepared via the Ibrik, French press, and Toddy methods for high acceptance levels, as well as for retention of bioactive components with antioxidant properties and abilities.

Key words: Tasting; antioxidants; barista; quality; cup.

\section{INTRODUCTION}

Coffee is a product with massive use, produced in over 70 countries (Liang et al., 2016; Oktaviani et al., 2020). It forms part of the most important agricultural chains in countries including Brazil, Vietnam, and Colombia, among others. For Colombians, this traditional beverage represents a symbol of national identity and pride. The quality of a cup of coffee depends on both climatic and postharvest processing factors, including the benefit, fermentation, and roasting conditions, as well as the variety and composition of the coffee processed (De Bruyn et al., 2017).

Numerous studies have addressed coffee functionality, based on its antioxidant composition, recommending its continuous consumption in order to obtain the health and sensory bounty provided thereby (Aguiar; Estevinho; Santos, 2016).

Certain authors have emphasized the role of coffee, fruits, grains, and vegetables in the diet as health-protecting agents, as they minimize oxidative stress, which is a precursor to many illnesses, including diabetes, Parkinson's disease, and various types of cancer (Aguiar; Estevinho; Santos, 2016; Oroian; Escriche, 2015). Additionally, the coffee roasting process generates products, during the Maillard reaction, which also exhibit antioxidant and free radical-trapping properties that are attributed to its phenolic content (Moreira et al., 2017).

Phenolic components act as antioxidants, via Single Electron Transfer (SET) and Hydrogen Atom Transfer (HAT). Phenolic components as the flavonoids, specifically phenolic acids and tannins has greatest function tin the coffee. Hydroxycinnamic acids, such as chlorogenic acid and ferulic acid, provide acidity and bitterness to the cup profile. Similarly, the presence of tannins in coffee is associated with the beverage's astringent notes. All of these metabolites support sensory quality and highlight the flavor of the toasted beans, which generate important benefits for human health, as reported in numerous scientific studies (Shao et al., 2015; Siswanto; Oguro; Imaoka, 2017; Yan et al., 2017; Bao et al., 2018; Imtiaz et al., 2019; Javed et al., 2020).

Roasting generates chemical changes in the antioxidant composition of coffee, as well as in its antioxidant activity. Such is the case of ferulic acid, during the roasting process, participates in decarboxylation reactions, in order to create phenolic compounds, thus increasing antioxidant content and simultaneously providing both bitter and acidic notes to the coffee (Lee et al., 2015).

The emergence of both new coffee preparations and the positioning of the barista culture constitute an emerging coffee market, which is characterized by the ingenuity, innovation, and motivation of connoisseurs and coffee lovers. Said preparations offer diverse sensorial profiles and antioxidant composition, in accordance with the preparation conditions employed (Ormaza-Zapata; Díaz-Arango; Rojano, 2019). This tendency makes way for the consumption of special coffees and the purchase of traditional and recent preparation methods. Thus, added value increases for other products derived from coffee (Angeloni et al., 2019).

The direct contact methods are characterized by leaving the water $\left(10{ }^{\circ} \mathrm{C}\right.$ to $\left.90{ }^{\circ} \mathrm{C}\right)$ in contact with the coffee for a certain period of time, in order that a mass transference phenomenon may occur. Therein, coffee solids pass to the water via lixiviation. Contact time varies for the methods under study, as does the coffee-water proportion, total preparation time, and water temperature (Ormaza-Zapata; Díaz-Arango; Rojano, 2019). 
The relationship between the preparation method, cup profile, and antioxidant compound composition has neither been established nor used as an opportunity to offer varieties of coffee with specific sensorial and functional characteristics to the market. Certain previous studies (Muñoz et al., 2020; Çelik; Gökmen, 2018) did not consider preparation method principle, but instead considered only those which are most popular in coffee shops or homes, and in some cases, only normalized coffee preparation procedures were applied, without consideration for comercial preparation methods. In some studies, preparation methods were neither correlated with the composition of various chemical antioxidant species, nor with the cupping test, which represents beverage acceptance by expert coffee tasters (Çelik; Gökmen, 2018). The objective of the present study is to determine antioxidant compound retention levels, as well as antioxidant capacity in the preparations under study. This will occur parallel with the development of an adequate cup profile in the preparation of coffee-based drinks, by way of five direct contact methods. The antioxidant metabolites studied were as follows: total phenols, flavonoids, condensed tannins, and hydroxycinnamic phenolic acids (chlorogenic acid, caffeic acid, p-coumaric acid, and ferulic acid). Antioxidant capacity was evaluated by way of the ABTS and ORAC methods.

\section{MATERIAL AND METHODS}

\subsection{Raw materials}

The parchment coffee (Coffea arabica L. var. Castillo) used was obtained from the municipality of Anserma, Caldas, Colombia, from San Rafael Farm, located at 1,750 $\mathrm{m}$ above sea level. It was grown at approximately $20{ }^{\circ} \mathrm{C}$, with an average relative humidity of $72 \%$. One thousand two hundred grams of each sample were processed, in triplicate, for each of the determinations made (Díaz-Arango; OrmazaZapata; Rojano, 2018).

\subsection{Physiochemical analyses}

The parchment was separated from the green bean, by way of a threshing process (Quantik, CR-2000, Quimbaya, Colombia). Samples were sifted, and only the excelso coffee that remained in the 14/64-inch sieve was used. Pods and other grains with defects were removed from groups one and two. The humidity content of the green beans was determined with the help of a forced convection stove (Dies, TH115FM, Antioquia, Colombia). The roasting process occurred at $180{ }^{\circ} \mathrm{C}+/-1{ }^{\circ} \mathrm{C}$, and $100 \%$ power, in a laboratory-scale roaster (Quantik, TC150 A/R, Quimbaya, Colombia), until beans with medium roast were obtained. After roasting, the samples continued to a milling process (Grindmaster 810, Mexico), which varied in accordance with the type of beverage preparation to be employed (fine, medium, or coarse) (Ormaza-Zapata; DíazArango; Rojano, 2019).

The size of the ground bean particulates was verified with the Taylor series method. Sample $\mathrm{pH}$ was measured with a digital $\mathrm{pH}$ meter (Lab-850; Schott Instruments ${ }^{\circledR}$, Germany). Soluble solids were determined with a digital refractometer (PAL-1, Atago ${ }^{\circledR}$, Japan), and were expressed in degrees Brix ( ${ }^{\circ}$ Brix). The weight of the ground coffee and that of the beverage were determined using a precision scale (Fénix-Plus, Bogotá, Colombia) for each preparation method: The Extraction Performance (EP) for each beverage was then calculated (Equation 1). Beverages were hermetically sealed

$\mathrm{RE}=\frac{\mathrm{m}_{2}}{\mathrm{~m}_{1}} \mathrm{x}^{\circ}$ Brix

in polypropylene plastic jars, and stored at $-40{ }^{\circ} \mathrm{C}$ for their subsequent preparation and analysis (Díaz-Arango; OrmazaZapata; Rojano, 2018).

Where $\mathrm{m}_{1}$ is the weight of the toasted, ground coffee in $\mathrm{g}, \mathrm{m}_{2}$ is the weight of the total beverage obtained in $\mathrm{g}$, and the ${ }^{\circ}$ Brix is the beverage's soluble solids percentage.

\subsection{Coffee beverage preparation with direct contact methods}

Five coffee beverage preparation methods, which employed the direct contact principle, were evaluated. The toasted and ground coffee were put in direct contact with the water at a given temperature, in accordance with the preparation method applied. Below, the procedure employed for each method is described:

-French press: Toasted, coarsely-ground coffee $(\geq 700$ microns) was used, and put in contact with hot water, at $90{ }^{\circ} \mathrm{C}$, for four minutes. Fourteen grams of coffee were mixed with $150 \mathrm{~mL}$ of water. Every two minutes, the mixture was stirred. A direct contact filtration system is utilized with this method, known as the piston cafetière, plunger, or French press.

-Midzudashi: Toasted, medium-ground coffee (500 - 700 microns) was used, as was cold water at $10{ }^{\circ} \mathrm{C}$. This method is equipped with a filtration system underneath, as well as a glass container with a plastic mesh netting. The coffee and water are in direct contact with ice.

-Toddy: One hundred grams of medium-ground (500 700 microns) coffee was mixed with $500 \mathrm{~mL}$ of cold water and $500 \mathrm{~g}$ of ice. The three ingredients were mixed in the plastic container. Contact time was 24 hours of refrigerator storage at $4{ }^{\circ} \mathrm{C}$. This content passed through a porous filter, with the help of gravity, to a glass jar, which was attached to the plastic container in order to obtain the final beverage. 
-Ibrik: This method, also known as the Turkish method, uses a low-volume metallic container which was placed on low heat until having boiled three consecutive times. Each time it boiled, the mixture was removed from the flame and left to rest for one minute. Fourteen grams of finely-ground coffee $(350-500$ microns) was mixed with $150 \mathrm{~mL}$ of hot water at $90{ }^{\circ} \mathrm{C}$. The total contact time between the water and coffee was four minutes.

-Percolator: Fifty-six grams of medium-ground coffee (500 - 700 microns) and $600 \mathrm{~mL}$ of water were mixed for four minutes by a recirculation system. In this case, a greater volume of water passed through the wide-pore filter containing coffee.

In Figure 1, the direct contact methods evaluated in the present study are shown.

\subsection{Coffee beverage cup profile analysis}

The respective beverages and the respective samples evaluated were prepared for the cup tasting (taken from minutes 2-9, every 30 seconds, in triplicate). The samples were evaluated with the Q.D.A. (Quantitative Descriptive Analysis) flavor profile, and provided a rating by the tester (three expert testers). The attributes evaluated in each case were: fragrance, aroma, acidity, bitterness, body, aftertaste, and overall impression. A form with a structured scale, containing values from 1-10, with
1 being the lowest and 10 being the highest rating, was used. Additionally, other descriptors were considered in the beverages' sensorial evaluation, which describe the presence of odd smells or flavors, product deterioration, contamination, or defects such as acridity, vinegar flavor, fermentation, astringency, age, rancidity, phenolic, earthy, or chemical flavors, among others. The results of the Q.D.A. cup tests were depicted on radial charts (OrmazaZapata; Díaz-Arango; Rojano, 2019).

\subsection{Sample preparation}

The beverages prepared with the five methods under study were diluted to fixed concentrations with distilled water, in order to perform antioxidant compound and capacity measurements (Rojano; Zapata; Sepúlveda, 2015).

\subsection{Total phenol determination}

Phenol determination was performed using FollinCiocalteu's colorimetric method. It constituted a pattern curve, using gallic acid as a standard. The results were expressed in $\mathrm{mg}$ of gallic acid.100g of sample $^{-1}$. The readings were performed at $760 \mathrm{~nm}$ in triplicate. A UVVIS spectrophotometer (Jenway, 6405, Essex, England) was used. The Follin-Ciocalteu reagent and gallic acid were obtained from the Merck trading house (Germany) (Ormaza-Zapata; Díaz-Arango; Rojano, 2019).

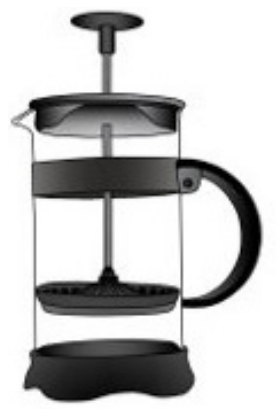

(a)

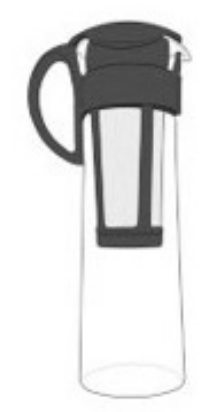

(d)

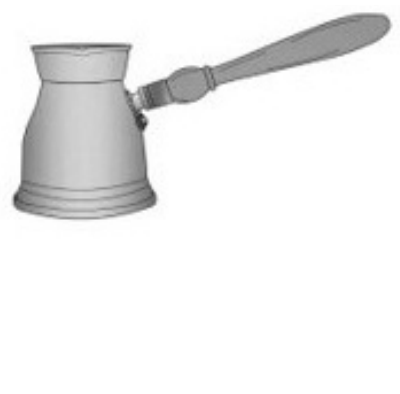

(b)

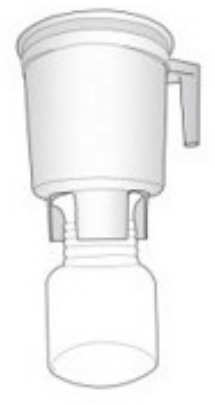

(c)

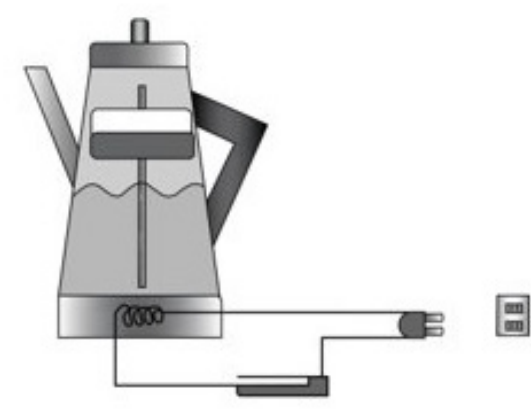

(e)

Figure 1: Direct contact coffee preparation methods a) French press b) Ibrik, c) Toddy, d) Midzudashi, and e) Percolator. Source: Authors. 


\subsection{Total flavonoid content}

Beginning with an aliquot of $0.5 \mathrm{~mL}$ of beverage sample solution, $0.5 \mathrm{~mL}$ of ethanolic solution was added, with $\mathrm{AlCl}_{3}$ at $2 \%$. After an hour of incubation at room temperature, the absorbency was determined to be $420 \mathrm{~nm}$. Catechin solutions (Sigma-Aldrich $\AA$, USA) were used, as was between 5-25 $\mu \mathrm{g} . \mathrm{mL}^{-1}$ of ethanol (Merck, Germany), for calibration curve construction. Total flavonoid content was calculated as $\mathrm{mg}$ equivalent to catechin. $100 \mathrm{~g} \mathrm{sample}^{-1}$. This procedure was carried out for each one of the samples in triplicate. The values presented correspond to the mean and standard deviation $( \pm)$. A UV-VIS (Jenway, 6405, Essex, England) spectrophotometer was used (Díaz-Arango; Ormaza-Zapata; Rojano, 2018).

\subsection{Condensed tannins}

Two hundred and thirty $\mu \mathrm{L}$ of the extract sample from each coffee beverage was taken, and $670 \mu \mathrm{L}$ of a recentlyprepared vanilla solution $\left(1 \mathrm{~g} .100 \mathrm{~mL}^{-1}\right)$ was added to $70 \%$ sulfuric acid. The mixture sat for 15 minutes at $20{ }^{\circ} \mathrm{C}$, and the spectrophotometric reading was taken at $500 \mathrm{~nm}$ and compared with the curve pattern used as standard $(+)$ - catechin. The results were expressed as $\mathrm{mg}$ of catechin equivalent. $100 \mathrm{~g}$ sample-1 $^{-1}$ (Ormaza-Zapata; Díaz-Arango; Rojano, 2019).

\subsection{Hydroxycinnamic phenolic acid content}

The coffee extracts were filtered $(0.45 \mathrm{~mm}$ pore size $)$ with dilutions in supra-pura water. The chromatographic conditions were: mobile acetonitrile phase/acidified water (phosphoric acid $\mathrm{pH}=2.5),(400: 600 \mathrm{v} / \mathrm{v})$. The phenolic components were eluated under the following conditions: flow of $1 \mathrm{~mL} \cdot \mathrm{min}^{-1}, 25^{\circ} \mathrm{C}$, and isochratic conditions. The UVvisible spectrum was traversed from $200-600 \mathrm{~nm}$ for all spikes. The identification and quantification of chlorogenic acid, caffeic acid, p-coumaric acid, and ferulic acid was performed via the standard external method in the beverages under study. All tests were performed in triplicate (Díaz-Arango; OrmazaZapata; Rojano, 2018).

\subsection{Antioxidant activity ABTS determination}

Measurements were taken at a $734 \mathrm{~nm}$ wavelength. One hundred $\mu \mathrm{L}$ were used as an extract of the coffee beverage samples at different times, with $900 \mu \mathrm{L}$ of the ABTS radical solution. Given 60 minutes to react at room temperature, in the dark, the change in reagent absorbency with an ABTS radical solution, with the sample solvent. The absorbency value was compared to the reference curve constructed with Trolox as a standard. For both compounds, the inhibitory concentration was determined to be $50 \%$ (IC50), as shown in Equation 3 (Percentage inhibition (PI)), and the results were expressed as TEACm values $\left(\mu \mathrm{mol}\right.$ Trolox.100 $\left.\mathrm{g} \mathrm{sample}^{-1}\right)$ (OrmazaZapata; Díaz-Arango; Rojano, 2019).
$\mathrm{PI}=\left[1-\left(\frac{A_{\text {sample }}-A_{\text {target sample }}}{A_{\text {standard }}-A_{\text {target standard }}}\right)\right] x 100$

\subsubsection{Oxygen Radical Absorption Capacity (ORAC) evaluation}

In the ORAC determinations, 6-hidroxi-2,5,7,8tetrametilchrome-2-carboxilic acid or Trolox (Merck, Germany) was used as standard with controlled temperature conditions, at $37^{\circ} \mathrm{C}$ and $7.4 \mathrm{pH}$. The readings were performed at an excitation wavelength of $493 \mathrm{~nm}$ and an excitation opening of five, one excitation emission of $515 \mathrm{~nm}$, emission opening of 13 , an attenuator of $1 \%$, and without attenuating plate. Fluorescein solutions of $1 \times 10^{-2} \mathrm{M}$ in phosphate buffer solution (PBS) (75 mM), 2.2'-Azinobis (2-amidinopropane) dichlorhydrate (AAPH) $0.6 \mathrm{M}$ in PBS $(75 \mathrm{mM})$ were employed. The beverage samples were prepared with 21 $\mu \mathrm{L}$ of fluorescein, $2.899 \mu \mathrm{L}$ of PBS, $30 \mu \mathrm{L}$ of the extract tested, and $50 \mu \mathrm{L}$ of AAPH. Trolox was used as a standard. The antioxidant protection effect was calculated using the differences between the areas of fluorescein between the target and sample below the decay curve, and the Trolox curve, and was expressed in $\mu \mathrm{mol}$ Trolox.100 $\mathrm{g} \mathrm{sample}^{-1}$ and TEAC $\mathrm{m}$, as shown in Equation 2 (Díaz-Arango; Ormaza-Zapata; Rojano, 2018). Said tests were performed in triplicate. The decrease in fluorescein intensity was made in a spectrofluroimeter (PerkinElmer LS-55, Beaconstield, UK). The fluorescein, PBS, sodium phosphate acid and the AAPH were acquired from the Aldrich Chem. Co trading house (Milwaukee, WI).

$\mathrm{ORAC}=\frac{\mathrm{AUC}_{\text {sample }}-\mathrm{AUC}_{\text {control }}}{\mathrm{AUC}_{\text {trolox }}-\mathrm{AUC}_{\text {control }}} \cdot \mathrm{f} .[$ trolox $]$

Where, $\mathrm{AUC}_{\text {sample }}$ is the area below the sample curve, $\mathrm{AUC}_{\text {control }}$ is the area below the curve for the standard, $\mathrm{AUC}_{\text {Trolox }}$ is the area below the curve for Trolox, and $\mathrm{f}$ is the extract dilution factor.

\subsection{Statistical analyses}

All determinations were made in triplicate and values expressed as averages the standard deviations $( \pm)$. The statistical differences were determined via variance analysis (ANOVA) and the Least Significant Difference test (LSD), with a value of $p<0.05$ for the comparison of means of each of the analyzed variables, antioxidant content, hydroxycinnamic phenolic acids, and antioxidant activity in the coffee beverages prepared via direct contact methods. The SAS statistical package was used. Linear regressions were calculated with a $95 \%(p<0,05)$ significance level, via the STATGRAPHICS Centurion XV statistical package (Ormaza-Zapata; Díaz-Arango; Rojano, 2019). 


\section{RESULTS}

The green, threshed coffee registered an initial humidity of $12 \%$, with which it guaranteed that the results obtained were comparable between them, based on samples with uniform humidity contents. The roasting process was performed with the same conditions for all samples evaluated. Certain physicochemical variables were analyzed, as presented in Table 1.

Beverage performance was highest for the Ibrik method, followed by the French press and Toddy, in that order. The Ibrik method may have presented high performance owing to the three consecutive times it was boiled during preparation. Water evaporation was thus generated the concentration of soluble and insoluble solids in the beverage obtained. The method which presented the most diluted beverage was that prepared with a percolator, owing to the constant recirculation generated with this method, as a consequence of coffee over-extraction. The methods with highest performance presented increased darkening, as a product of their solid concentrations. Toddy, although it is a cold method of preparation, presented high performance, in contrast to the Midzudashi cold method, which presented greater fluidity and clarity in the beverage obtained. The ANOVA indicated a significant difference between preparation methods applied and performances obtained $\mathrm{p}<0.05$.

The soluble solids $\left({ }^{\circ}\right.$ Brix) presented the highest values in the preparations performed with the Ibrik, French press, and Toddy methods, followed by that of Midzudashi, and lastly, the percolator. These results corroborate the relationship with beverage performance obtained by each of the direct contact methods evaluated. Said results indicated that the preparation method influenced sugar, organic acid, salt, and other watersoluble compounds' dilution. No significant effect was found in terms of preparation temperature for beverage solid soluble concentration $(p>0.05)$, but the preparation method applied did have a significant effect $(\mathrm{p}>0.05)$.

The $\mathrm{pH}$ of the beverage prepared with the Toddy method was the highest of all of the beverages, followed by that of the percolator, Ibrik, and French press methods. This assertion was made evident with the Toddy method, but not with the Midzudashi method, which is also prepared cold. In the latter, there was no agitation during preparation, while with the Toddy method, there was. This permitted the complete solubilization of the organic acids, and the resulting alkalization of the cold beverage. With the French press and Ibrik methods, there was no mixture homogenization. With the percolator method, there was constant water recirculation and over-extraction during preparation. The $\mathrm{pH}$ value is related to the concentration of organic acids present in the coffee. Variance analysis indicated a significant difference $(\mathrm{p}<0.05)$ between the beverage $\mathrm{pH}$ and the preparation method applied.

Total phenol content was high with use of the Ibrik method, followed by that of the French press and Toddy methods, with values of 3,024, 2,212.9, and $1969.8 \mathrm{mg}$ of gallic acid.100 g sample ${ }^{-1}$, respectively (Figure 2 ). The lowest phenol content was obtained with the percolator and Midzudashi methods, in decreasing order. The preparation temperature did not have a significant effect $(p<0.05)$ on total phenol retention, but the preparation method applied did $(\mathrm{p}>0,05)$. The Midzudashi and percolator preparation methods had the lowest performance with the lowest total phenol content, possibly owing to the effect of dilution in these preparation methods.

It seems that high temperatures during beverage preparation did not affect total phenol retention, with contact times of approximately four minutes.

Flavonoid concentration increased with the Ibrik, French press, and Toddy methods, with values of 3,089.9 $\mathrm{mg}, 2,367.9 \mathrm{mg}$, and 2,263.1 $\mathrm{mg}$, respectively, expressed as milligrams of catechin equivalent.100 g sample ${ }^{-1}$ (Figure 3). The flavonoid content was lower for percolator and Midzudashi methods, and similar there between. The preparation method caused a significant effect $(\mathrm{p}>0.05)$ on flavonoid retention in the beverages obtained.

In terms of tannin retention in the beverages, prepared with different direct contact methods (Figure 4), their concentration was greater with the Ibrik method, followed by the Toddy and Midzudashi methods, at 162.6, 123.5, and 107.3 $\mathrm{mg}$, respectively, expressed as $\mathrm{mg}$ of catechin equivalent.100 g sample ${ }^{-1}$. The French press method had a content slightly under that reported for Midzudashi. The percolator method registered the lowest tannin content. Statistical analysis revealed a significant difference $(p<0,05)$ in the condensed tannin concentration, given the beverage preparation method.

Table 1: Physicochemical parameters of coffee beverages prepared with different direct contact methods.

\begin{tabular}{ccccc}
\hline Method & Beverage performance & ${ }^{\circ}$ Brix & pH & Contact time \\
\hline French press & $16.45( \pm 0.27) \mathrm{a}$ & $2.00( \pm 0.03) \mathrm{a}$ & $4.87( \pm 0.01) \mathrm{a}$ & $4 \mathrm{~min}$. \\
Midzudashi & $9.28( \pm 0.60) \mathrm{b}$ & $1.13( \pm 0.02) \mathrm{b}$ & $4.82( \pm 0.01) \mathrm{b}$ & 24 hours \\
Toddy & $13.52( \pm 0.40) \mathrm{c}$ & $2.00( \pm 0.01) \mathrm{a}$ & $5.23( \pm 0.01) \mathrm{c}$ & $24 \mathrm{hours}$ \\
Ibrik & $16.54( \pm 0.27) \mathrm{a}$ & $2.10( \pm 0.01) \mathrm{c}$ & $4.88( \pm 0.02) \mathrm{a}$ & $4 \mathrm{~min}$. \\
Percolator & $7.84( \pm 0.23) \mathrm{d}$ & $1.00( \pm 0.02) \mathrm{d}$ & $4.94( \pm 0.03) \mathrm{d}$ & $4 \mathrm{~min}$. \\
\hline
\end{tabular}

The average values $(n=3)$ with different letters in the same column indicate statistical differences at a $5 \%$ significance level $(p<0.05)$. 


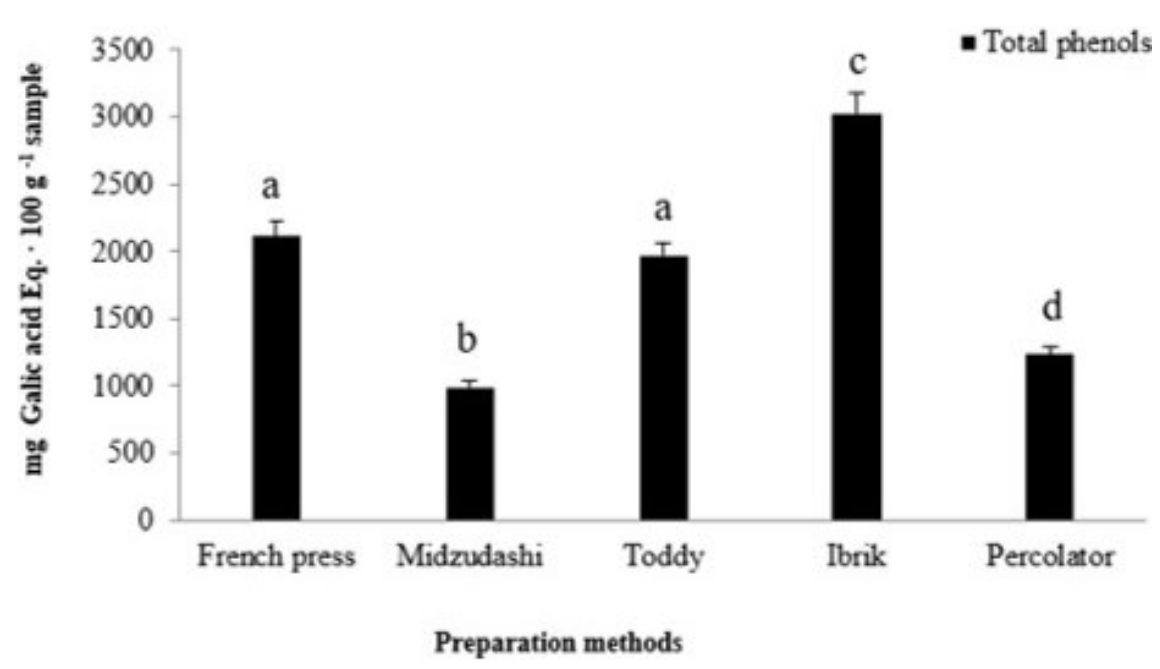

Figure 2: Total phenol content with direct contact coffee preparation methods. Average values $(n=3)$ with different letters in the same variable indicate statistical differences at the $5 \%$ significance level $(p>0.05)$.

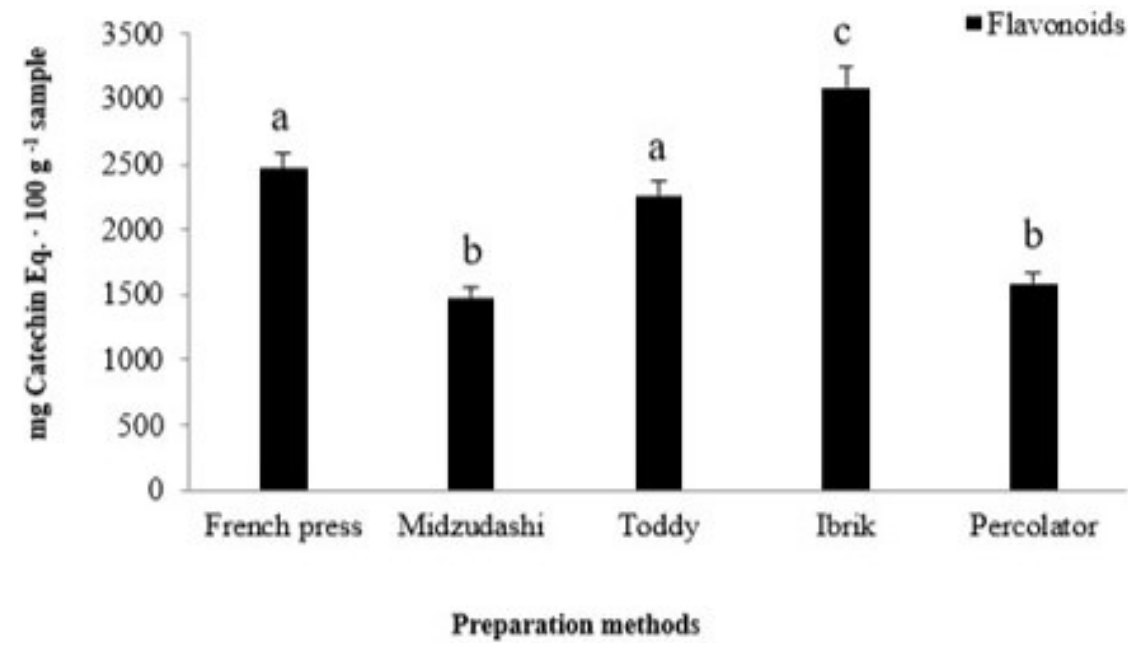

Figure 3: Flavonoid content with direct contact preparation methods. Average values $(n=3)$ with different letters in the same variable indicate statistical differences at the $5 \%$ significance level $(p>0.05)$.

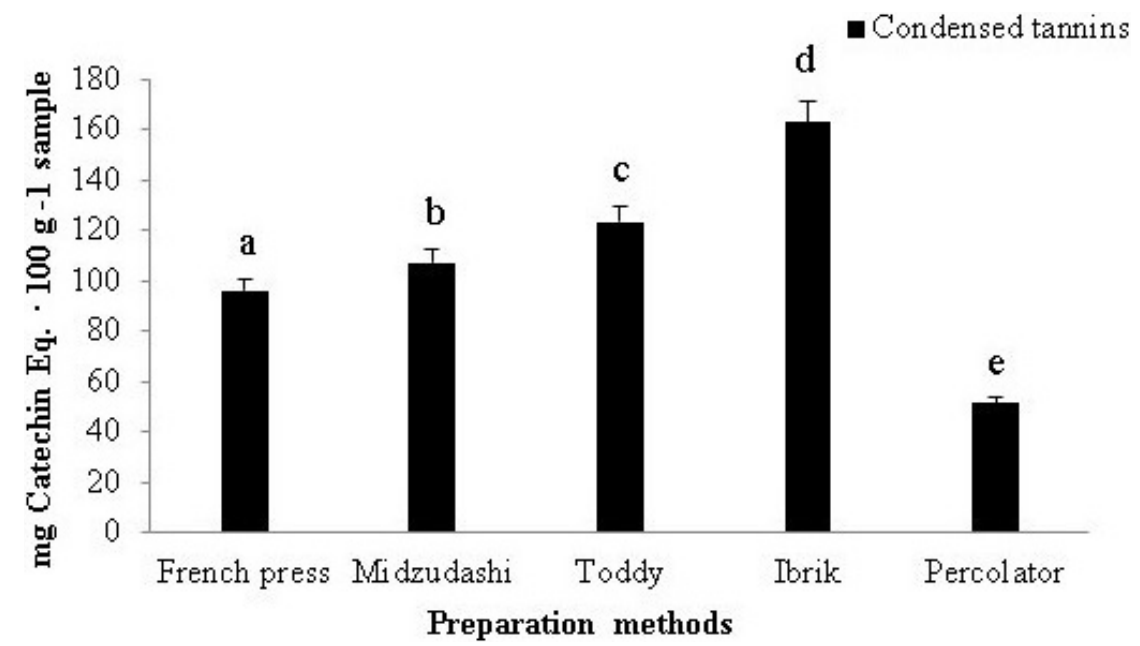

Figure 4: Condensed tannin content in direct contact preparation methods. Average values $(n=3)$ with different letters in the same variable indicate statistical differences at the $5 \%$ significance level $(p>0.05)$. 
In Figure 5, the content of hydroxycinnamic acid content in the beverages prepared with five direct contact methods may be observed. The hydroxycinnamic acid that occurs in the greatest concentrations, in the five direct contact methods evaluated, was chlorogenic acid. The chlorogenic acid content was greater in the French press method, followed by that of the Ibrik and percolator methods. Caffeic acid content was obtained only with the French press and Midzudashi methods. With the Toddy, Ibrik, and percolator methods, this component was not identified. P-coumaric acid was registered in the highest amounts with the percolator and Ibrik methods. The other methods presented similar concentrations of this compound. Ferulic acid presented the same behavior as p-coumaric acid. Only the French press and Midzudashi methods contained the four hydroxycinnamic acids evaluated. The ANOVA indicated a significant effect $(\mathrm{p}<0.05)$ of the preparation method on beverage hydroxycinnamic acid concentrations. The cold methods, Toddy and Midzudashi, had the lowest chlorogenic acid content.

The values obtained for antioxidant capacity with the ABTS and ORAC methods were statistically different $(\mathrm{p}<0.05)$ (Figure 6). The ABTS activity values, in descending order, were for Ibrik, Toddy, French press, Midzudashi, and percolator methods. With the ORAC method, antioxidant capacities were obtained in descending order for Ibrik, French press, Toddy, Percolator, and Midzudashi methods. These results indicate a positive correlation in the expression of antioxidant components in beverages ready for consumption. Percolator and Midzudashi presentations contained the lowest antioxidant capacity registered in the evaluated methods. No significant effect $(p<0.05)$ was observed between beverage preparation temperature and antioxidant activity in the components studied.

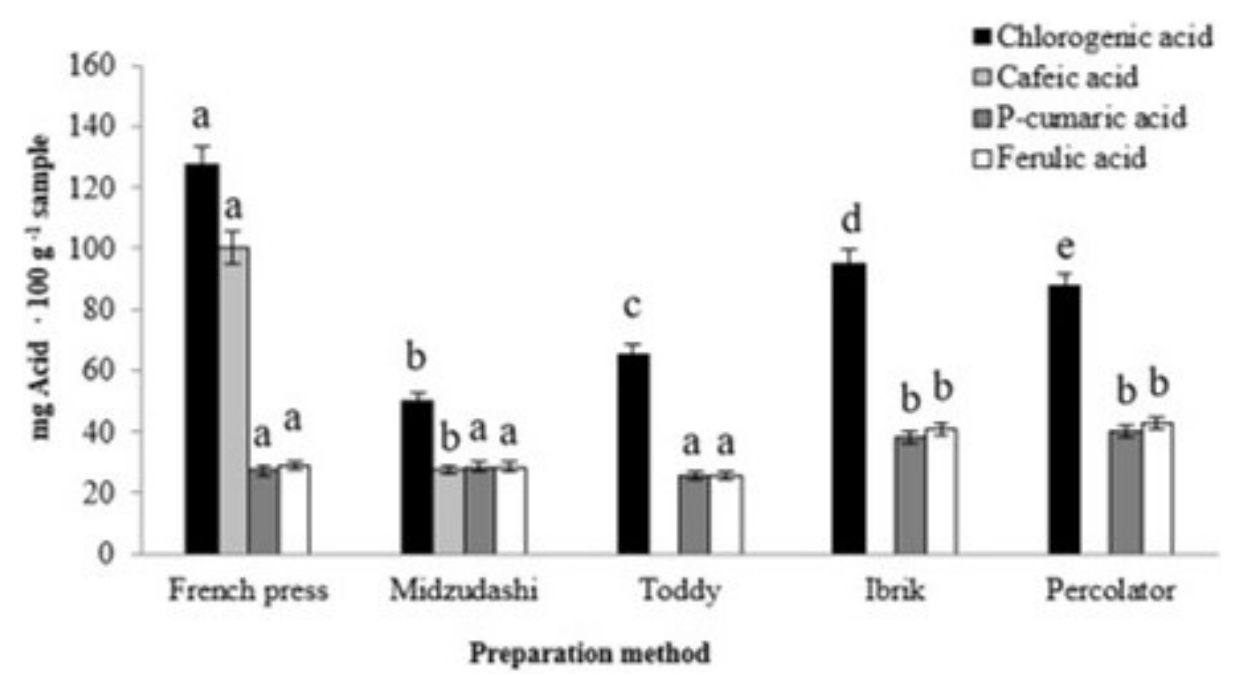

Figure 5: Hydroxycinnamic phenolic acid content in beverages prepared with direct contact methods. Average values ( $n=3)$ with different letters in the same variable indicate statistical differences at the $5 \%$ significance level $(p>0.05)$.

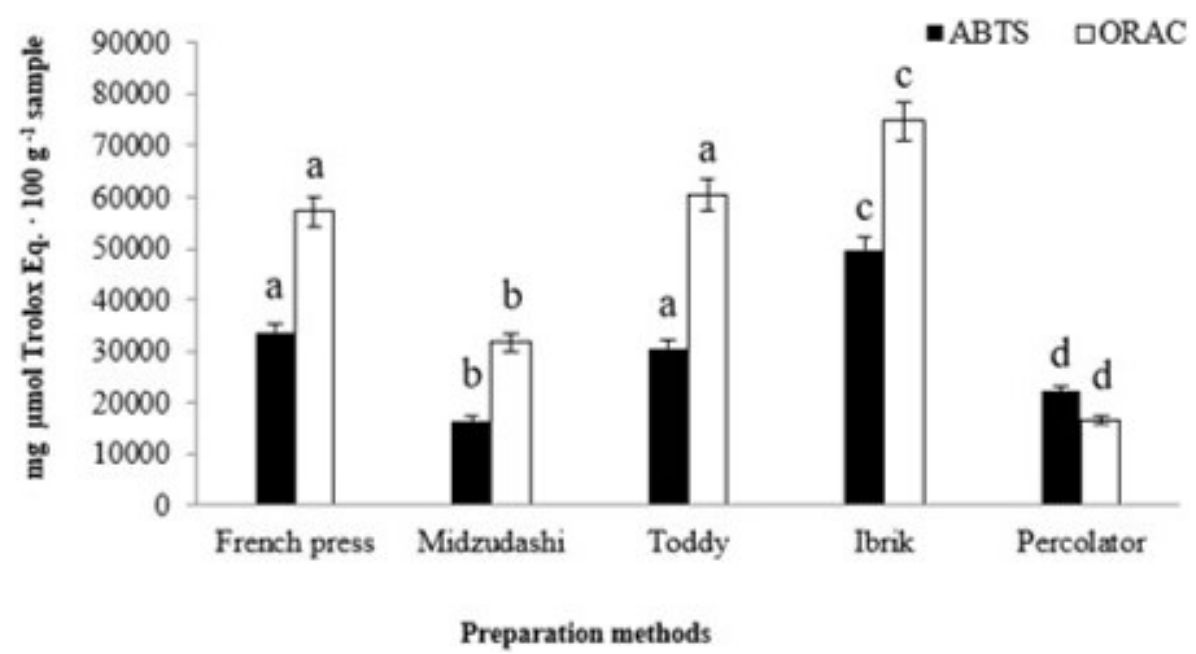

Figure 6: Antioxidant capacity for ABTS and ORAC methods in beverages prepared with direct contact methods. Average values $(n=3)$ with different letters in the same variable indicate statistical differences at the $5 \%$ significance level $(p>0.05)$. 
The ratings given to the beverages prepared with different direct contact methods presented various profiles, with respect to coffee patterns (excelso U.G.Q) (Figure 7). This indicates that the cup profile for a coffee beverage will correspond to the preparation method applied. The ANOVA determined significant differences $(p<0.05)$ between the coffee preparation method and cup sensorial profile obtained. The French press method presented low acidity and marked bitter notes, as compared to the standard sample. The drink prepared with the Midzudashi method had body and a greater overall impression rating than that of the standard, although the other attributes were at the same level as the standard. The beverage prepared with the Toddy method obtained exactly the same rating as that of the Midzudashi method. The Ibrik method possessed low acidity and marked bitter notes, compared to the U.G.Q. excelso coffee standard. The remaining descriptors had the same rating as excelso coffee. Finally, the beverage prepared with the percolator presented a marked aftertaste and the lowest overall impression rating of all of the methods evaluated.

Finally, the Toddy and Midzudashi methods presented higher overall impression ratings than the hot preparation methods compared. The tannin concentrations indicated in Figure 4 show low and minimally significant concentrations, and none of the tasters indicated astringent, undesirable notes in the evaluated samples.

\section{DISCUSSION}

The roasting process occurred under set conditions for all samples analyzed. Thus, the thermal degradation level was similar in the samples employed for the subsequent antioxidant and antioxidant capacity analyses (Díaz-Arango; OrmazaZapata; Rojano, 2018) and cup profiles.

Water temperature, contact time, and mixture homogenization permitted an increase in solubility of all components in hot water during beverage preparation, as in the case of the Ibrik preparation (Yüksel; Barut; Bayram, 2020). Certain baristas recommend the consumption of cold coffees, given that the greasy sensation, bitterness, and acidity is lower in these preparation methods, which use approximate temperatures from 8 to $21{ }^{\circ} \mathrm{C}$ (Rao; Fuller, 2018; Angeloni et al., 2019; Baumann; Wheeler; Alfreds, 2020).

Other coffee components that affect the acidity and $\mathrm{pH}$ of the beverage prepared include the caffeine, trigonelline, chlorogenic acids, citric acid, acetic acid, and formic acid present in the beans (De Luca et al, 2016).

Excelso U.G.Q. coffee contains high concentrations of the phenolic acids, which are responsible for its higher antioxidant activity, as observed in Figure 2, and coincides with that reported in numerous studies (Rao; Fuller, 2018; Muñoz et al., 2020; De Abreu Pinheiro et al., 2021), including on comparison to certain types of Colombian coffee.

The thermic decomposition of phenols during roasting permits caffeine liberation in the bean, and this contributes to the cup profile of the coffee beverage, lending body, strength, and bitter notes thereto (Cheng et al., 2016; Swak; Ji; Jeong, 2017). Thus, the bitter flavor is balanced with biological functionality, and as such, coffee may be prepared in a variety of ways. Polyphenol concentrations, however, come at the expense of bitterness, including chlorogenic acid concentrations (De Bruyn et al., 2017).
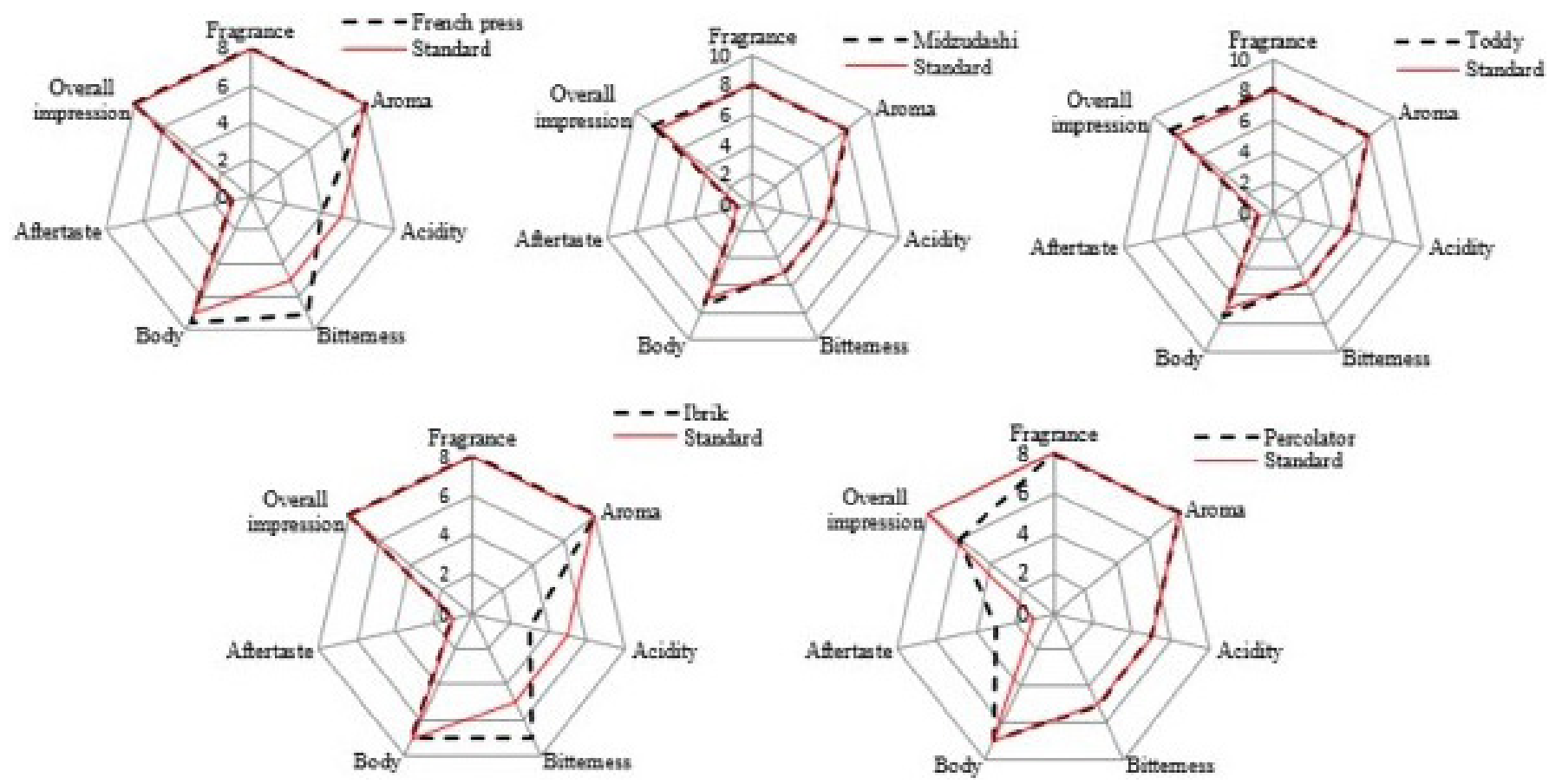

Figure 7: Sensorial profile of the beverages prepared via the principle of contact, compared to the U.G.Q. pattern. Average values $(n=3)$. 
Phenols intervene in the synthesis of products which are secondary to the Maillard reaction by way of temperature action (Moreira et al., 2017) such as melanoidins, which act as antioxidants that lend flavor, color, and serve as reducing agents. Additionally, they are sensitive to $\mathrm{pH}$ change, participate in transesterification reactions, and influence caffeine, chlorogenic acid, and caffeic acid concentrations in the beverages prepared highly water soluble (Lee et al., 2017). The incorporation of phenols in the diet helps to regulate oxidative stress and protects the body from diabetes and cardiovascular illness. Similarly, their antiallergenic, anti-inflammatory, and antimicrobial properties have been proven (Mussatto, 2015).

Phenol content reported with Expresso and Mocca methods were 5,000 and $3,000 \mathrm{mg}$ of gallic acid.100 g sample $^{-1}$, respectively (Ormaza-Zapata; Díaz-Arango; Rojano, 2019b), which presented values superior to those reported in the present study for the Ibrik and French Press methods. These presented higher levels of phenols in the beverage obtained. On comparison of the phenol content reported for the Toddy and French Press methods in the present study, with the Clever drip and RS-16 methods, similarities were found in total phenol concentrations, which were approximately $2,000 \mathrm{mg}$ of gallic acid.100 $\mathrm{g} \mathrm{sample}^{-1}$ for the four methods compared (Ormaza-Zapata; Díaz-Arango; Rojano, 2019).

In a previous study, it was found that flavonoid content, with the Expresso method, was 10,705.2 mg of catechin equivalent.100 g sample ${ }^{-1}$ (Ormaza-Zapata; Díaz-Arango; Rojano 2019b), which constitutes a value almost three times as large as that reported in the present study with the Ibrik method, which herein, had a concentration of 3,089.9, mg of catechin equivalent. $100 \mathrm{~g} \mathrm{sample}^{-1}$.

Multiple studies indicate that flavonoids have anticancerogenic, anti-inflammatory, and antiartherosclerotic properties, and help to prevent illnesses including Alzheimer's and Parkinson's disease (Chen; Chen, 2013; Kurzawa-Zegota et al., 2012). Additionally, they contribute to the reduction in prevalence of coronary illness and to macrobian equilibrium, on an intestinal level (Cardona et al., 2013).

Condensed tannin concentrations were obtained for coffee beverages prepared with the Expresso, Vietnamese, RS16 , and Clever methods of 197.4, 146.1, and $120.5 \mathrm{mg}$ of catechin equivalent.100 $\mathrm{g}$ of sample $\mathrm{e}^{-1}$. The present study reports tannin concentrations for the beverages obtained with the Ibrik and Toddy methods that coincide with the tannin range reported by various authors (Ormaza-Zapata; Díaz-Arango; Rojano, 2019; OrmazaZapata; Díaz-Arango; Rojano, 2019b), while the remaining direct contact methods presented lower tannin concentrations, between 50 and $100 \mathrm{mg}$ of catechin equivalent. $100 \mathrm{~g}$ of sample $\mathrm{e}^{-1}$.

The presence of tannins in the cupping test relates closely to astringent notes found in the beverage obtained, and are substances with great functional value (Caetano et al., 2017). In terms of the results obtained, the tannin concentration achieved in each preparation had astringent notes at an optimal interval, given that their presence in the sample did not change the sensorial rating; similar ratings were conferred upon the U.G.Q. excelso standard. From a bio-functional point of view, tannins possess antihemorrhagic and anti-inflammatory properties, and help to prevent premature aging and degenerative disease. Moreover, tannins generate an undesirable tactile sensation in coffee, which causes constriction, frowning, and dryness in the oral cavity's mucous membrane, and influence the bitterness sensation. This is generated by the degree of polymerization of the condensed tannin molecules. These interact synergistically with saliva proteins, and impart an astringent sensation to the palate (Chira; Teissedre, 2015; Watrelota; Badet-Murat; Waterhouse, 2018).

On comparison of hydroxycinnamic acid content quantified with the direct contact methods (chlorogenic, caffeic, p-coumaric, and ferulic acids) to other preparation types described extensely in other studies, they were found to coincide in a range between 20 and $120 \mathrm{mg} .100 \mathrm{~g}$ of sample ${ }^{-1}$, approximately (Ormaza-Zapata; Díaz-Arango; Rojano, 2019; Ormaza-Zapata; Díaz-Arango; Rojano, 2019b; Angeloni et al., 2019; Muñoz et al., 2020).

Hydroxycinnamic acids influence the sensory properties and antioxidant activity in coffee-based drinks. The chlorogenic acids provide acidity, astringency, and bitter notes to the drink (Cheng et al., 2016), as well as the caffeine and flavonoids present. Similarly, in concordance with the present study, it was reported that, in Coffea arabica samples, the majority hydroxycinnamic acid was chlorogenic acid, while caffeic and coumaric acid presented the lowest concentrations (Cheong et al., 2013). The relative change in chlorogenic acid content in arabica coffee and its isomers depends on the region in which it originated, the degree of roasting, and method of preparation (Liang et al., 2016).

As indicated, the existence of a direct correlation between non-enzymatic browning and the antioxidant capacity of Colombian roasted coffee, generated by the Maillard reaction, as well as by phenolic compounds belonging to the hydroxycinnamic acid group (chlorogenic, caffeic, coumaric, and ferulic), melanoidins, caffeine, and certain volatile components (Contreras-Calderón et al., 2016).

The methods which obtained the highest ratings in the bitterness attribute were the Ibrik and French press methods, which coincides with the fact that these methods also had higher total phenol and flavonoid retention, as these are responsible for the bitter notes in coffee beverages, as previously indicated in figures two and three. Additionally, chlorogenic acid levels were also high with the French press and Ibrik methods. These acids also fortify the bitter flavor of the cup. Similarly, it was observed that the methods with highest extraction performance (Table 1) presented satisfactory qualifications in the overall impression category (Figure 7). 
Midzudashi and Toddy scores did not coincide with sensorial profile results reported by Córdoba et al. (2019), evaluated in cold beverages, given that the scores indicated are a great deal lower than those reported herein, which uses the UGQ pattern as a reference, despite having used the same discriptors, which include aroma, aftertaste, acidity, body, and overall impression.

In accordance with the findings reported by Yilmaz, Hacibekiroğlu and Kolak (2014) the Ibrik or Turkish method presents the highest ABTS activity, in comparison with three other popular preparation methods (Americano, espresso, and mocha), and displayed a value similar to that indicated in this study. In terms of antioxidant activity, another study indicated that the coffee prepared with French presses presented greater antioxidant activity than beverages prepared with the Ibrik or Turkish method, as a result of employed dilution, coffee-water contact time, and preparation method (Çelik; Gökmen, 2018). This last report did not coincide with the results of the present study, given that antioxidant activity was greater with the Ibrik method than with the French press method, although arabica coffee was also used.

Dripper methods such as Vietnamese, Clever, Kinto, Yama, RS-16, V60 Kalita and V60 presented ABTS antioxidant activity with values between 20,000 and $35,000 \mathrm{mg} \mu \mathrm{mol}$ Trolox equivalent.100 $\mathrm{g} \mathrm{sample}^{-1}$, while ORAC antioxidant activity was between 28000 and 55000 $\mathrm{mg} \mu \mathrm{mol}$ Trolox equivalent. $100 \mathrm{~g}$ sample ${ }^{-1}$. It was observed that the methods of French Press, Toddy and Ibrik in the present study, presented a higher expression of antioxidant compounds in relation to the dripper methods reported in a previous study (Ormaza-Zapata; Díaz-Arango; Rojano, 2019).

\section{CONCLUSIONS}

Direct contact preparation methods such as the Ibrik, French press, and Toddy methods, in that order, presented high antioxidant compound content between those which underscore total phenol, flavonoid, and condensed tannin content, and their antioxidant activity was also significant (ABTS and ORAC). Hydroxycinnamic acid content was high with the French press and Ibrik methods. Similarly, in the cup profile, bitterness, attributes, and body were highlighted with use of these methods, with ratings equal to a U.G.Q. excelso standard pattern in the remaining sensorial attributes. Finally, it is recommended that coffee-based beverages be prepared with the Ibrik, French press, or Toddy methods, so as to guarantee consumption of a greater antioxidant compound content, and their expression, as defined sensorial, attributes are attractive for consumers of hot and cold coffee, and are similar to those of a premium quality coffee.

\section{ACKNOWLEDGEMENTS}

The authors are grateful for the support provided by the Food Science Laboratory at the Universidad Nacional de Colombia, Medellín branch and the Sensorial Analysis and Coffee Industrialization Laboratory at the Universidad de Caldas and, during the preparation and development of the present study.

\section{REFERENCES}

AGUIAR, J.; ESTEVINHO, B. N.; SANTOS, L. Microencapsulation of natural antioxidants for food application e the specific case of coffee antioxidants. Trends in food science \& technology, 58:21-39, 2016.

ANGELONI, G. et al. Characterization and comparison of cold brew and cold drip coffee extraction methods. Journal of the Science of Food and Agriculture, 99(1):391-399, 2019.

BAO, L. et al. Chlorogenic acid prevents diabetic nephropathy by inhibiting oxidative stress and inflammation through modulation of the Nrf2/HO-1 and NF-KB pathways. International Immunopharmacology, 54: 245-253, 2018.

BAUMANN, S.; WHEELER, B.; ALFREDS, K. L. Cold brew system and method for making cold brew coffee or tea extract. Patent US20120021108A1. 2012. Available in: <https://patents.google.com/patent/ US20120021108A1/en.> Access in: March, 7, 2020.

CAETANO, N. S. et al. Valorisation of spent coffee grounds: Production of biodiesel via enzymatic catalysis with ethanol and a co-solvent. Waste and Biomass Valorization, 8(6):1981-1994, 2017.

CARDONA, F. et al. Benefits of polyphenols on gut microbiota and implications in human health. The Journal of Nutritional Biochemistry, 24(8):1415-1422, 2013.

ÇELIK, E. E.; GÖKMEN, V. A study on interactions between the insoluble fractions of different coffee infusions and major cocoa free antioxidants and different coffee infusions and dark chocolate. Food Chemistry, 255:8-14, 2018.

CHEN, A. Y.; CHEN, Y. C. A review of the dietary flavonoid, kaempferol on human health and cancer chemoprevention. Food Chemistry, 138(4):2099-2107, 2013.

CHENG, B. et al. Influence of genotype and environment on coffee quality. Trends in Food Science \& Technology, 57(Part A):20-30, 2016. 
CHEONG, M. W. et al. Volatile composition and antioxidant capacity of arabica coffee. Food Research International, 51(1):388-396, 2013.

CHIRA, K.; TEISSEDRE, P. L. Chemical and sensory evaluation of wine matured in oak barrel: Effect of oak species involved and toasting process. European Food Research and Technology, 240(3):533-547, 2015.

CONTRERAS-CALDERÓN, J. et al. Evaluation of antioxidant capacity in coffees marketed in Colombia: Relationship with the extent of non-enzymatic browning. Food Chemistry, 209: 162-170, 2016.

CÓRDOBA, N. et al. Effect of grinding, extraction time and type of coffee on the physicochemical and flavour characteristics of cold brew coffee. Scientific reports, 9(8440):1-12, 2019.

DE ABREU PINHEIRO, F. et al. Arabica and conilon coffee flowers: Bioactive compounds and antioxidant capacity under different processes. Food chemistry, 336(127701):1-10, 2021.

DE BRUYN F. et al. Exploring the impacts of postharvest processing on the microbiota and metabolite profiles during green coffee vean production. Applied and environmental microbiology, 83(1):1-16, 2017.

DE LUCA, S. et al. Characterization of the effects of different roasting conditions on coffee samples of different geographical origins by HPLC-DAD, NIR and chemometrics. Microchemical Journal, 129:348$361,2016$.

DÍAZ-ARANGO, F. O.; ORMAZA-ZAPATA, A. M.; ROJANO, B. A. Efecto de la Tostión del Café (Coffea arabica L. var. Castillo) sobre el Perfil de Taza, Contenido de Compuestos Antioxidantes y la Actividad Antioxidante. Información Tecnológica, 29(4):31-42, 2018.

IMTIAZ, S. M. et al. The potential involvement of an ATPDependent potassium channel-opening mechanism in the smooth muscle relaxant properties of tamarix dioica roxb. Biomolecules, 9(11):722, 2019.

JAVED, F. et al. Pharmacological evaluation of analgesic, anti-inflammatory and antipyretic activities of ethanolic extract of Indigofera argentea Burm. f. Journal of Ethnopharmacology, 259:e112966, 2020.

KURZAWA-ZEGOTA, M. et al. The protective effect of the flavonoids on food-mutagen-induced DNA damage in peripheral blood lymphocytes from colon cancer patients. Food and Chemical Toxicology, 50(2):124-129, 2012.
LEE, L. W. et al. Modulation of the volatile and non-volatile profiles of coffee fermented with Yarrowia lipolytica: II. Roasted coffee. LWT- Food Science and Technology, 80:32-42, 2017.

LEE, L. W. et al. Coffee fermentation and flavor - An intricate and delicate relationship. Food Chemistry, 185:182-191, 2015.

LIANG, N. et al. Interactions between major chlorogenic acid isomers and chemical changes in coffee brew that affect antioxidant activities. Food Chemistry, 213:251-259, 2016.

MOREIRA, A. S. P. et al. Transglycosylation reactions, a main mechanism of phenolics incorporation in coffee melanoidins: Inhibition by maillard reaction. Food Chemistry, 227: 422-431, 2017.

MUÑOZ, A. E. et al. Evaluation of differences in the antioxidant capacity and phenolic compounds of green and roasted coffee and their relationship with sensory properties. LWT - Food Science and Technology, 128(109457):1-9, 2020.

MUSSATTO, S. I. Generating biomedical polyphenolic compounds from spent coffee or silverskin. Coffee in health and disease prevention. London: Elsevier, p.96-106, 2015.

OKTAVIANI, L. et al. Fermentation of coffee pulp using indigenous lactic acid bacteria with simultaneous aeration to produce cascara with a high antioxidant activity. Heliyon, 6 (e04462): 1-8, 2020.

ORMAZA-ZAPATA, A. M.; DÍAZ-ARANGO, F. O.; ROJANO, B. A. The effect of gravity-drip filtration methods on the chemical and sensorial properties of coffee (Coffea arabica L. var. Castillo). Coffee Science, 14(3):415-426, 2019.

ORMAZA-ZAPATA, A. M.; DÍAZ-ARANGO, F. O.; ROJANO, B. A. The effect of pressure filtration coffee preparation methods (Coffea arabica L. var. Castillo) on antioxidant content and activity, and beverage acceptance. Dyna, 86(209):261-270, 2019b.

OROIAN, M.; ESCRICHE, I. Antioxidants: Characterization, natural sources, extraction and analysis. Food Research International, 74:10-36, 2015.

RAO, N. Z; FULLER, M. Acidity and antioxidant activity of cold brew coffee. Scientific report, 8(e16030):1-9, 2018.

ROJANO, B.; ZAPATA, I.; SEPÚLVEDA, J. Efecto del tiempo de almacenamiento sobre las propiedades fisicoquímicas, probióticas y antioxidantes de yogurt saborizado con mortiño (Vaccinium meridionale $\mathrm{Sw}$ ). Información Tecnológica, 26(2):17-28, 2015. 
SHAO, P. et al. Microwave-assisted extraction and purification of chlorogenic acid from by-products of Eucommia Ulmoides Oliver and its potential anti-tumor activity. Journal of Food Science and Technology, 52(8):4925-4934, 2015.

SISWANTO, F. M.; OGURO, A.; IMAOKA, S. Chlorogenic acid modulates hypoxia response of Hep3B cells. Personalized Medicine Universe, 6:12-16, 2017.

SWAK, H. S.; JI, S.; JEONG, Y. The effect of air flow in coffee roasting for antioxidant activity and total polyphenol content. Food Control, 71:210-216, 2017.

WATRELOTA, A. A.; BADET-MURAT, M.; WATERHOUSE, A. L. Oak barrel tannin and toasting temperature: Effects on red wine condensed tannin chemistry. LWT - Food Science and Technology, 91:330-338, 2018.

YAN, Y. et al. Chlorogenic acid inhibits hepatocellular carcinoma in vitro and in vivo. The Journal of Nutritional Biochemistry, 46:68-73, 2017.

YILMAZ, P. K; HACIBEKIROĞLU, I.; KOLAK, U. Effect of roasting on antioxidant and anticholinesterase capacities of coffee. Journal of Food and Nutrition Research, 53(3):232-239, 2014.

YÜKSEL, A. N.; BARUT, K. T. O.; BAYRAM, M. The effects of roasting, milling, brewing and storage processes on the physicochemical properties of Turkish coffee. LWT - Food Science and Technology, 131(109711):1-8, 2020. 